\title{
The Pathognomic Radiologic Features of Gout in the Fingers and Review of the Literature, Including the Latest Drug Therapy
}

\author{
Mehdi Hossaini $^{*}$, Eric Tetteroo ${ }^{2}$, Frank M. A. Slaats ${ }^{3}$, Annechien Beumer ${ }^{4}$ \\ ${ }^{1}$ Department of Orthopaedic Surgery, Catharina Hospital, Eindhoven, The Netherlands \\ ${ }^{2}$ Department of Radiology, Amphia Hospital Breda, Breda, The Netherlands \\ ${ }^{3}$ Department of Rheumatology, Amphia Hospital Breda, Breda, The Netherlands \\ ${ }^{4}$ Department of Orthopaedic Surgery, Amphia Hospital Breda, The Netherlands \\ Email: *hossaini.ariyan@gmail.com
}

Received June 27, 2013; revised July 27, 2013; accepted August 4, 2013

Copyright (c) 2013 Mehdi Hossaini et al. This is an open access article distributed under the Creative Commons Attribution License, which permits unrestricted use, distribution, and reproduction in any medium, provided the original work is properly cited.

\begin{abstract}
Gout is one of the most common inflammatory arthritides that predominantly affects the first metatarsophalangeal joint. The underlying inflammatory process is elicited by the deposition of monosodium urate (MSU) crystals in the affected joint that are termed tophi and which may in the course of chronic gout progress into subcutaneous depositions of tophi. In this case report, we present a patient (PID: 6925981) who was seen in our outpatient department with a first episode of tophaceous gout in the finger, an infrequently seen condition that mostly affects older men with long-term gout. We discuss the case in view of the current literature on diagnosis and treatment of tophaceous gout.
\end{abstract}

Keywords: Gout; Tophi; Interphalangeal Joint; Finger; Monosodium Urate; Arthritis

\section{Introduction}

Gout is a form of arthritis and it is one of the earliest recognized clinical entities in medical history. Gout was first identified by the Egyptians in 2640 BC and later described by Hippocrates and Galen [1]. The underlying pathophysiology is an inflammatory process induced by deposition of monosodium urate (MSU) crystals in articular and periarticular tissues [2], and the presence of these negatively birefringent crystals in the aspirated specimen of the affected joint is a prerequisite for the diagnosis of gout. The first sign of a gouty arthritis is usually an acute painful attack in the first metatarsophalangeal joint of the foot, a condition termed podagra [3], while other joints are less frequently affected [4]. Gout is strongly associated with an increased level of uric acid in the blood but hyperuricaemia is not required for the development of gout and patients with hyperuricaemia may remain asymptomatic throughout their lives [5]. Further, gout is often associated with obesity, metabolic syndromes, chronic kidney and/or cardiovascular diseases [3, 6]. The use of certain drugs such as diuretics (Furose mide, Hydrochlorothiazide), immunosuppressant (Суc-

\footnotetext{
${ }^{*}$ Corresponding author.
}

losporin) and low dose Aspirin may also be correlated with hyperuricaemia and gout [7]. The incidence of gout is rising worldwide and this may be related to aging and the increased prevalence of obesity [8-10]. In addition, inadequate treatment and sedentary lifestyles with high intakes of alcohol, protein and fructose (the only carbohydrate known to increase uric acid levels) may lead to chronic forms of gout with periodic flare-ups [11-13].

\section{Case Report}

An eighty year old male patient with a long history of gout visited our outpatient department complaining of axial pain in the proximal interphalangeal (PIP) joint of his left third finger that was present for three weeks. Soft tissue swelling was seen on the dorsal and palmar sides of PIP with slightly decreased range of motion. Radiographic examination (Figure 1) showed sharply marginated juxta-articular erosions and marked soft tissue swelling. Blood examination showed an elevated uric acid level of $0.58 \mathrm{mmol} / \mathrm{L}$ (normal $<0.30$ ). Over the years, the patient had painful flares of gout limited to his pedal joints when going on vacations in Mediterranean areas, likely due to dietary changes including alcohol 

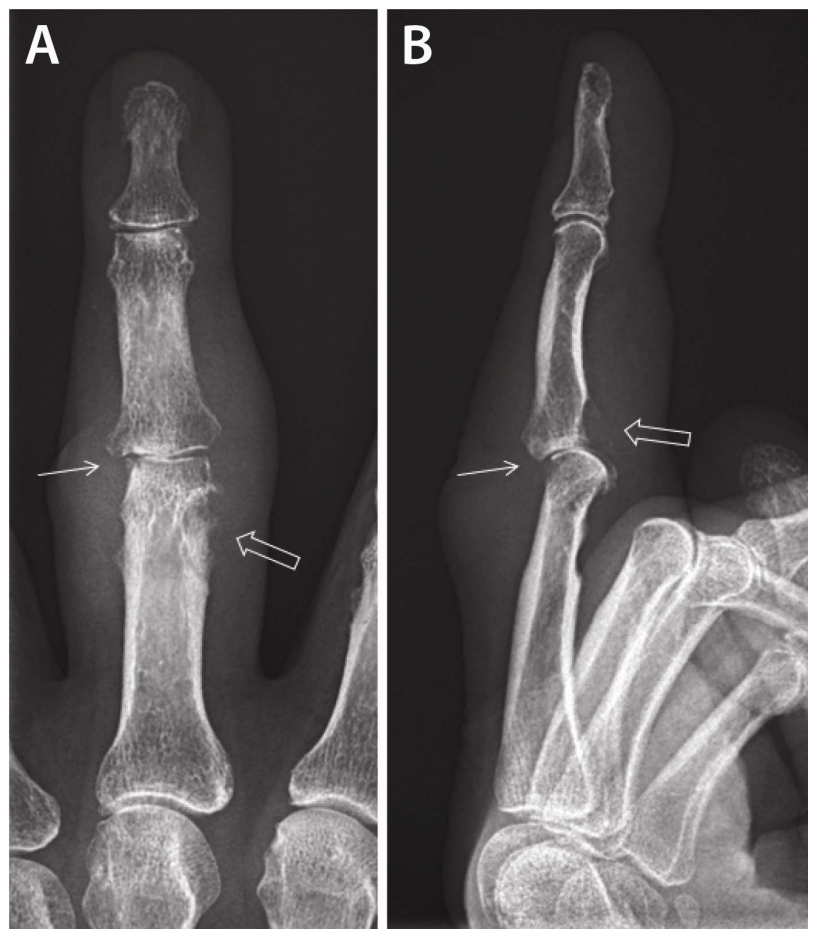

Figure 1. Posteroanterior (A) and lateral (B) third finger radiographs show at the proximal interphalangeal joint typical juxta-articular "punched-out" erosions with sclerotic borders and overhanging edges (open arrows). There is marked periarticular hyperdense soft tissue swelling representing monosodium urate crystal deposits in thickened synovia. These so-called tophi are pathognomonic for gout. Note joint space narrowing due to cartilage destruction, leading to secondary degenerative osseous changes and subluxation which can be observed in chronic gout (arrows).

consumption. Further, the patient was treated with Colchicine by the rheumatologist and he was aware of the dietary restrictions advised to control his uric acid levels. Next to gout, the patient was diagnosed with Polycythemia Vera and he suffered from polyglobulia, thrombocytosis and microcytosis. The patient did not have any symptomatic cardiovascular and gastrointestinal abnormalities except for mild diarrhea related to Colchicine treatment. After we confirmed tophaceous gout Allopurinol was started in order to decrease the serum uric acid levels that resulted in remission of the gouty attack in the patient's finger.

\section{Discussion}

\subsection{Chronic Gout}

In the chronic course of gout, densely packed MSU crystals may deposit subcutaneously in (peri) articular tissue with subsequent joint damage and painful episodes years after the first acute painful attack [14]. Subcutaneous tophi deposition are usually visible in the helix of the ear, over the olecranon process and on the Achilles tendons, and less frequently in the finger joints $[14,15]$. There are several case reports on tophaceous gout in the fingers $[16,17]$ and in most of the patients the gouty attacks are localized in the proximal interphalangeal joints. Further, it seems that the incidence of gouty attacks is increasing in the past decade, notably in men older than 60 years with the foot and spine being the most affected sites [18]. In the present case, Polycythemia Vera induced blood dyscrasia and increased cell turnover may produce hyperuricaemia leading to gout [19-21]. Further, poor compliance with drug treatment [22] and high protein and fructose intake [12,13] during the vacations may also have contributed to the development of tophi deposition in the finger joint of the present patient. In case of symptomatic gout, Colchicine is the mainstay therapy for prophylaxis and treatment of acute attacks while urate-lowering drugs such as Allopurinol are employed for longterm management and prophylaxis of gout $[5,23]$. It should be noted that novel therapies such as anti-interleukin-1 (Anakinra, Canakinumab, Rilonacept), a new xanthine oxidase inhibitor (Febuxostat) and uricolytic drugs (Rasburicase, Pegloticase) seem to be beneficial in treating refractory chronic gout. In addition, they seem to improve health-related quality of life, particularly by preventing cardiovascular comorbidities [24-26]. Drug treatment aimed at lowering uric acid levels will subsequently lead to tophi resolution and regain of full range of motion. If drug treatment is inadequate in mobilizing tophaceous deposits, then operative tophectomy should be considered in order to avoid permanent joint deformity and loss of function [27].

\subsection{Radiologic Features of Gout}

From a radiological point of view, characteristic changes only occur in the chronic stage of gout. Only $45 \%$ of patients with gout manifest radiographic bone changes, and then only 6 to 8 years after the initial attack. Furthermore, radiographic abnormalities alone are not sufficiently sensitive and specific for the diagnosis of gout [28]. Gouty arthritis usually has an asymmetrical polyarticular distribution with a predilection for the small joints of hands and feet. The radiographic hallmarks of gout are well-defined "punched-out" erosions with sclerotic margins in a marginal and juxta-articular distribution, with overhanging edges. Periarticular soft tissue swelling due to tophi deposition in synovial tissue is common. Tophi are also found to deposit in cartilage, bone, bursae and other places throughout the body. The periarticular tophi may be hyperdense due to the crystals and are pathognomonic for gout. In addition, absence of periarticular osteopenia (as seen in other common inflammatory arthritides) and preservation of joint space until late stages of the disease are other clues to the diagnosis. Because 
the radiographic findings may at times be confusing and appear quite unusual, it may be helpful to remember, "When in doubt, think gout" [29]. However, the refinement in detecting tophi deposition using ultrasound [30, 31] and dual energy computed tomography (CT) has made it easier to diagnose gout [32]. This will enable us to more accurately determine the consequence of tophi depositions on joint deformity and functional impairments and to monitor the effect of urate-lowering drugs on tophi formation. These outcomes might encourage new therapeutic approaches in the management and follow-up of patients with gout.

\section{Conclusion}

In conclusion, patients with chronic gout may complain of pain in the interphalangeal joints as a result of tophi deposition that may lead to (peri) articular changes visible on radiographic examinations. Adequate therapy includes dissuading the patient from high alcohol, protein and fructose diets and treatment with up-to-date drugs.

\section{REFERENCES}

[1] G. Nuki and P. A. Simkin, "A Concise History of Gout and Hyperuricemia and Their Treatment," Arthritis Research \& Therapy, Vol. 8, Suppl. 1, 2006, pp. S1-S5.

[2] L. Punzi, A. Scanu, R. Ramonda and F. Oliviero, "Gout as Autoinflammatory Disease: New Mechanisms for More Appropriated Treatment Targets,” Autoimmunity Reviews, Vol. 12, No. 1, 2012, pp. 66-71. doi:10.1016/j.autrev.2012.07.024

[3] W. Zhang, M. Doherty, E. Pascual, T. Bardin, V. Barskova, P. Conaghan, J. Gerster, J. Jacobs, B. Leeb, F. Liote, G. McCarthy, P. Netter, G. Nuki, F. Perez-Ruiz, A. Pignone, J. Pimentao, L. Punzi, E. Roddy, T. Uhlig and I. Zimmermann-Gorska, "EULAR Evidence Based Recommendations for Gout. Part I: Diagnosis. Report of a Task Force of the Standing Committee for International Clinical Studies Including Therapeutics (ESCISIT),” Annals of the Rheumatic Diseases, Vol. 65, No. 10, 2006, pp. 1301-1311. doi:10.1136/ard.2006.055251

[4] E. Roddy, W. Zhang and M. Doherty, "Are Joints Affected by Gout Also Affected by Osteoarthritis?” Annals of the Rheumatic Diseases, Vol. 66, No. 10, 2007, pp. 1374-1377. doi:10.1136/ard.2006.063768

[5] P. Richette and T. Bardin, “Gout,” Lancet, Vol. 375, No. 9711, 2010, pp. 318-328. doi:10.1016/S0140-6736(09)60883-7

[6] H. K. Choi and E. S. Ford, "Prevalence of the Metabolic Syndrome in Individuals with Hyperuricemia," The American Journal of Medicine, Vol. 120, No. 5, 2007, pp. 442-447. doi:10.1016/j.amjmed.2006.06.040

[7] M. Marangella, "Uric Acid Elimination in the Urine. Pathophysiological Implications," Contributions to $\mathrm{Ne}$ phrology, Vol. 147, No. 2005, pp. 132-148.

[8] K. L. Wallace, A. A. Riedel, N. Joseph-Ridge and R.
Wortmann, "Increasing Prevalence of Gout and Hyperuricemia over 10 Years among Older Adults in a Managed Care Population,” The Journal of Rheumatology, Vol. 31, No. 8, 2004, pp. 1582-1587.

[9] P. C. Robinson, T. R. Merriman, P. Herbison and J. Highton, "Hospital Admissions Associated with Gout and Their Comorbidities in New Zealand and England 19992009,” Rheumatology, Vol. 52, No. 1, 2013, pp. 118-126. doi:10.1093/rheumatology/kes253

[10] G. Trifiro, P. Morabito, L. Cavagna, C. Ferrajolo, S. Pecchioli, M. Simonetti, E. Bianchini, G. Medea, C. Cricelli, A. P. Caputi and G. Mazzaglia, "Epidemiology of Gout and Hyperuricaemia in Italy during the Years 2005-2009: A Nationwide Population-Based Study," Annals of the Rheumatic Diseases, Vol. 72, No. 5, 2013, pp. 694-700. doi:10.1136/annrheumdis-2011-201254

[11] H. K. Choi, K. Atkinson, E. W. Karlson, W. Willett and G. Curhan, "Alcohol Intake and Risk of Incident Gout in Men: A Prospective Study,” Lancet, Vol. 363, No. 9417, 2004, pp. 1277-1281. doi:10.1016/S0140-6736(04)16000-5

[12] H. K. Choi, K. Atkinson, E. W. Karlson, W. Willett and G. Curhan, "Purine-Rich Foods, Dairy and Protein Intake, and the Risk of Gout in Men,” The New England Journal of Medicine, Vol. 350, No. 11, 2004, pp. 1093-1103. doi:10.1056/NEJMoa035700

[13] H. K. Choi and G. Curhan, "Soft Drinks, Fructose Consumption, and the Risk of Gout in Men: Prospective Cohort Study,” British Medical Journal, Vol. 336, No. 7639, 2008, pp. 309-312. doi:10.1136/bmj.39449.819271.BE

[14] T. Gibson, “Clinical Features of Gout,” In: M. Hochberg, Ed., Rheumatology, Mosby, Edinburg, 2003, pp. 19191928.

[15] R. Wortmann, "Gout and Hyperuricaemia,” In: G. Firestein, Ed., Kelley's Textbook of Rheumatology, Saunders Elseviers, Philadelphia, 2008, pp. 1481-1524.

[16] A. Alexandroff, N. Kirkham and N. Nayak, "A Painless, Swollen Finger (for 20 Years),” Lancet, Vol. 371, No. 9618, 2008, p. 1114. doi:10.1016/S0140-6736(08)60487-0

[17] J. M. Geiderman, "An Elderly Woman with a Warm, Painful Finger,” The Western Journal of Medicine, Vol. 172, No. 1, 2000, pp. 51-52. doi:10.1136/ewjm.172.1.51

[18] F. Bolzetta, N. Veronese, E. Manzato and G. Sergi, "Tophaceous Gout in the Elderly: A Clinical Case Review," Clinical Rheumatology, Vol. 31, No. 7, 2012, pp. 11271132. doi:10.1007/s10067-012-1956-x

[19] A. M. Denman, L. Szur and B. M. Ansell, "Joint Complaints in Polycythaemia Vera," Annals of the rheumatic diseases, Vol. 23, No. 1964, pp. 139-144.

[20] M. Denman, L. Szur, and B. M. Ansell, "Hyperuricaemia in Polycythaemia Vera," Annals of the Rheumatic Diseases, Vol. 25, No. 4, 1966, pp. 340-344.

[21] L. R. Wasserman, "Polycythemia Vera: Its Course and Treatment; Relation to Myeloid Metaplasia and Leukemia,” Bulletin of the New York Academy of Medicine, Vol. 30, No. 5, 1954, pp. 343-375.

[22] B. A. Briesacher, S. E. Andrade, H. Fouayzi and K. A. 
Chan, "Comparison of Drug Adherence Rates among Patients with Seven Different Medical Conditions," Pharmacotherapy, Vol. 28, No. 4, 2008, pp. 437-443. doi:10.1592/phco.28.4.437

[23] A. T. Eggebeen, “Gout: An Update,” American Family Physician, Vol. 76, No. 6, 2007, pp. 801-808.

[24] K. M. Jordan, "Up-to-Date Management of Gout," Current Opinion in Rheumatology, Vol. 24, No. 2, 2012, pp. 145-151.

[25] F. Perez-Ruiz, L. Martinez-Indart, L. Carmona, A. M. Herrero-Beites, J. I. Pijoan and E. Krishnan, “Tophaceous Gout and High Level of Hyperuricaemia are Both Associated with Increased Risk of Mortality in Patients with Gout,” Annals of the Rheumatic Diseases, 2013, in Press.

[26] E. Suresh and P. Das, "Recent Advances in Management of Gout," Monthly Journal of the Association of Physicians, Vol. 105, No. 5, 2012, pp. 407-417.

[27] R. H. Gelberman, D. H. Doty and M. L. Hamer, "Tophaceous Gout Involving the Proximal Interphalangeal Joint," Clinical Orthopaedics and Related Research, Vol. 147, 1980, pp. 225-227.

[28] A. Brower and D. Flemming, “Gout”, In: Arthritis: In
Black and White, WB Saunders, Philadelphia, 1997, pp. 325-341.

[29] J. A. Jacobson, G. Girish, Y. Jiang and B. J. Sabb, "Radiographic Evaluation of Arthritis: Degenerative Joint Disease and Variations," Radiology, Vol. 248, No. 3, 2008, pp. 737-747. doi:10.1148/radiol.2483062112

[30] P. V. Chowalloor and H. I. Keen, “A Systematic Review of Ultrasonography in Gout and Asymptomatic Hyperuricaemia," Annals of the Rheumatic Diseases, Vol. 72, No. 5, 2013, pp. 638-645. doi:10.1136/annrheumdis-2012-202301

[31] E. De Miguel, J. G. Puig, C. Castillo, D. Peiteado, R. J. Torres and E. Martin-Mola, "Diagnosis of Gout in Patients with Asymptomatic Hyperuricaemia: A Pilot Ultrasound Study," Annals of the Rheumatic Diseases, Vol. 71, No. 1, 2012, pp. 157-158. doi:10.1136/ard.2011.154997

[32] H. K. Choi, L. C. Burns, K. Shojania, N. Koenig, G. Reid, M. Abufayyah, G. Law, A. S. Kydd, H. Ouellette and S. Nicolaou, "Dual Energy CT in Gout: A Prospective Validation Study," Annals of the Rheumatic Diseases, Vol. 71, No. 9, 2012, pp. 1466-1471.

doi:10.1136/annrheumdis-2011-200976 